\title{
Telecom Policy Innovation: the Role of Free Spectrum and Telecommunication Development in Rural Ghana
}

\author{
Idongesit Williams'
}

\begin{abstract}
Every nation wants to achieve Universal Access of telecommunication services due to its importance to the economy and national life. Unfortunately in sub-Saharan Africa, telecommunication services are either scarce or non-existent in rural areas. However, previous telecommunication policies have enabled the provision of various network technologies in Africa. What type of policy is needed to push these telecommunication services into rural areas? This paper discusses the importance of issuing a using Free Spectrum policy to as an incentive to small telecom network operators in Africa. Ghana is used as a test case.
\end{abstract}

Keywords: Policy innovation; telecom market incentive; rural telecommunications; universal access.

' Centre for Communications, Media and Information Technologies, Department of Planning,Aalborg University Copenhagen, Lautrupvang IA, 2nd floor, DK-2750 Ballerup, Denmark. Email: idong@plan.aau.dk 


\section{Introduction}

This article is about the use of free spectrum as an incentive to cheaper telecom network providers to invest in rural areas of sub-Saharan Africa. The African country used as a test here is Ghana. The prime motive of every business man is to make profit in any venture he pursues. Whereas the role of the public sector is to provide public goods in which telecommunications is one of them. The current trend in policy making has been to find common grounds by which private interest will interoperate with public interest to provide public good. One of the policy initiatives very critical to attracting private sector participation is the provision of market incentives by the public sector in the telecommunication industry. These market incentives are aimed at facilitating the demand and supply side of telecommunication services. For the public sector, its aim is to ensure universal access of telecommunications and the private sector is seen as a tool to achieving this fit because of budgetary shortfalls in providing infrastructure in all areas of the economy (The free dictionary by Farlex, 20II). For the private investor these market incentives give room for the reduction of operational cost as well as other transaction costs as he enters the market. It makes the market attractive for the private sector. The reduction of cost, coupled with other factors like competition will eventually enable the subscribers of the public good to access the good at a reasonable cost.

However, even though the result of the above narrated relationship is always aimed at by policy makers, the reality on ground is always far from the most desired expectations. Taking Sub-Saharan Africa as an example, the outcome of many telecommunication policies few years down the line has presented a new challenge which affects the ultimate aim of attaining Universal access of telecommunications services. While policy makers and the various stakeholders have been able to facilitate broad telecommunications coverage in commercially viable areas, the rural areas and the non- commercially viable areas experience little or no coverage at all. The economic disparity experienced by the two groups in a sub-Saharan African country makes the dream of reduced operational and transaction cost in rural areas difficult. Telecom network operators deploy telecommunication infrastructure at a huge cost hence attracting a return on investment in rural areas becomes a difficult mountain to climb.
With this challenge, it is imperative to look at innovative ways of either strengthening existing policy measures through innovative policies or come up with new policy initiatives that will enable the penetration of telecommunication services in rural areas. The main crux of new policies has to centre on different ways that will influence the reduction of cost of deployment of infrastructure.

Secondly, there are different type of telecom network technologies under the Mobile and fixed network categories of network technologies. Policy makers have to do cost benefit analysis to ascertain which type of network technology can be deployed at a cheaper cost in rural areas.

Presently in cosmopolitan areas of sub-Saharan Africa, the Global System for Mobile Communications (GSM), the Universal Mobile Telecommunications Service (UMTS) and the High Speed Packet Access technologies (HSPA) family of mobile network technologies are ubiquitous. Other network technologies like WiMAX, Wi-Fi, and VSAT etc. are used in a small scale compared to the ubiquitous technologies. It is necessary to find out which technology if deployed will reduce the cost of access by the subscriber.

Previous policy initiatives have enabled some interesting scenarios. In a study conducted on the Ghanaian telecommunications sector, there is a picture that reflects the situation in other African countries. There are more Wi-Fi, VSAT operators than the GSM and UMTS operators. Certain policy factors enable this phenomenon (Frempong, 200I). The reason is simple, the market entry requirements for the GSM and UMTS operators in Africa is much higher than that of the $\mathrm{Wi}-\mathrm{Fi}$ operators. This is because there are certain restrictions to the number of GSM operators that the regulatory authority of a country can allow based on their strategic, technical and economic interests. But for the Wi-Fi etc. operators, their operation is downstream hence their entry requirement is much lower because it promotes ICTs at the grass root. This makes the use of Wi-Fi, VSAT, WiMAX etc. more likely technologies that can be used for rural areas. And nowadays WiMAX and $\mathrm{Wi}-\mathrm{Fi}$ and other technologies can be used as an overlay to a GSM network to extend coverage to rural areas. Another cheaper initiative is the use of $\mathrm{Wi}$-Fi point-to-point link using Line-of-Sight ranges as a backhaul transmission link into an interior with no alternative backhaul transmission link. 
It is imperative to realign new policy thoughts in line with these developments to serve the rural areas. In this article, discussion will centre on how unlicensed spectrum can be used as incentive for local Wireless Access Network providers as an incentive to invest in rural areas in Ghana. The significance of this article is to contribute to the discussion of using unlicensed spectrum to facilitate rural telecommunication penetration. If the cost of licencing and spectrum is removed, it will attract investors to invest in rural areas, knowing that the recurring cost of regulatory charges and spectrum fees is out of the way. The cost of deploying technologies like $\mathrm{Wi}-\mathrm{Fi}$ will be reduced over time and the cost of access to the service by the villager will also reduce. Ghana is used as a test study because of the infrastructure it has in place from the International bandwidth to the last mile and the potential for implementing this policy. Secondly, Ghana's rural areas do have the same features as many rural areas in many sub-Saharan countries.

The outline of the article is as follows. Under the theoretical discussion, the role of market incentive in facilitating the telecommunications market and the different forms of spectrum administration and allocation are discussed. The main methods used for gathering data and the results gathered from these methods are also included in this article. Finally, the discussion centres on the rational for free spectrum as a market incentive for small network operators to operate in rural Ghana.

\section{Market incentives and the telecommunications market}

Market incentives have been used in many African countries to facilitate the telecommunication markets in Sub-Saharan Africa. Many incentives have been used over the years to stimulate the diffusion of telecommunication services. Tax incentives is one of them, Nigeria in 2001, Nigeria granted 5 years tax holiday incentives to four new mobile network operators who were pioneers in the country (Bankole, 2009). One of the aims of the incentive was the reduction of initial cost of deploying infrastructure in the country. In 200I Nigeria had 266461 mobile subscribers in the first year of implementing the 5 year tax holiday. In 2005, five years later, the number of subscribers grew to 18, 295, 896 subscribers (NCC, 20II). In 2005 Universal Licence was granted to all telecommunication operators with only a single licence offering. That moved the active number of telecommunication operators from 8 to 25 (Bilesanmi, 20II). Currently 20 are operating.
Today, the number of mobile telephony subscribers has grown to 103, 347, 158 subscribers (NCC, 20II). Ghana, Mozambique and $U$ ganda allow free repatriation of profits, and tax incentives to foreign companies, this includes foreign network operators (FDI, 1999). These have equally made their markets attractive to foreign network providers. However, quite unlike Nigeria, Ghana, Uganda and Mozambique do not have major indigenous network providers. However, this market incentive has attracted major investments into the market. In Ghana there is stiff competition between MTN and Millicom Ghana Itd (Tigo), both are subsidiaries of South African and a United States based company. Due to the financial incentive of repatriation of profits, the companies are in stiff competition to gain more subscribers which eventually translates to more money. Ghana has a population of almost 24 Million citizens (Ghana Statistical Service, 2010). By December 2010 Ghana had 17436949 mobile telephone subscribers. MTN had 8721249 subscribers while Tigo brand could boast of 3999262 mobile subscribers (NCA, 20II). The other network operators had a combination of 8316438 subscriptions in their books. If all Ghanaians were to own one mobile telephone per person, it would mean that Universal Access would almost be achieved by the rate at which the competition is going.

Another form of incentive deployed in Africa is infrastructure development. Although Africa still has a deficit of infrastructure development, many African countries have made effort to provide telecommunication infrastructure. In Ghana, the government has liberalised infrastructure delivery. Today there are private companies involved separately in the development of international, national and last mile bandwidth in Ghana (Ghana Connect, 2010). This has enabled competition already in the broadband market. In Nigeria, MTN and GLO Mobile is also involved in the development of national bandwidth. Similar initiatives also took place in South Africa. The competition in the development and deployment of national bandwidth encourages innovation and the reduction in the cost of access to broadband by ISPs, Companies and homes, depending on who the subscriber to the service is. This has led to the reduction in the cost of broadband. In Ghana, the cost of access of accessing a fibre optic network for broadband has reduced from US $\$ 4500$ to US $\$ 2100$ monthly (myitghana, 20I0).

Market incentives are really important, even though they may not always present the required result. However they will produce some results. 


\section{Different forms of licencing and spectrum allocation}

It is important to look at the theory of the proposed market incentive and to explain why the choice of unlicensed commons is adopted for this article. Deregulation is the removal or simplification of government rules and regulations that constrain the operation of market forces (Sullivan etal, 2002). The general idea is that few or no regulations has the potential to raise competition, enhance higher productivity, enhance efficiency which will in turn lead to low prices for the consumer. In telecommunications, one of the most important components of market entry is spectrum and licence acquisition. This can be done separately or together depending on each country. One of the reasons spectrum is regulated is because it is a scarce resource. Its demand is often higher than the supply. Hence to enhance technical efficiency of allocated spectrum it is often regulated. In a monopolistic market, spectrum was granted as state concession. However in a competitive market, technical efficiency alone is not the only reason why regulation is needed, spectrum regulation is another way of regulating the competition ensuing in the telecommunications market. This is because of the uneven network capacities of the competitors in the market. So to ensure fairness regulation is needed.

However, regulation of spectrum can either be by command and control, use of market mechanisms or unlicensed commons(Openspectrum, 20II)(SatapathyandPeha, 1996). For the command and control, a regulator decides on the use and assignment of spectrum. For the market control, spectrum is sold in the free market and for the unlicensed commons, spectrum is granted without any licence.

Command and control is the most common practice in many countries. Under this practice licences are either allocated via auctions, public tenders (beauty contest), and the lottery or on a first come first serve basis (Falch, 2010). Generally the auction is preferred by governments as millions of dollars are accrued by governments as a result of potential network providers competing to outbid each other. The Spectrum allocation is part of the licence fee of operation. With the market mechanism scheme, the regulatory authority in many cases do grant permission to licence holders to either trade with their licences or carry out any form of exchange or rent of unused spectrum by the network operator to another network operator. However, some regulatory bodies practice the combination of the three licence regulatory models for different network technologies being regulated in the country. This depends on the technology the sector regulator intends to promote at a particular time. In many countries, regulators grant preference to certain based mostly on their ability to attract returns in terms of taxes and other forms of revenue to the government of the day.

Spectrum in many cosmopolitan areas is scarce. However in rural areas, there are lots of unused spectrums. However, even though spectrum is a scarce resource it has been discovered that much of the allocated spectrum sit idle at any given time whenever a system is not transmitting. Hence Spectrum sharing has been proposed as a solution of solving scarcity (Peha, 20II). It is a way of sharing spectrum without causing excessive harmful interference with traffic from competing operators. With this technique competing operators can share spectrum, giving room to more traffic. With this new technique in place is it still necessary to adopt the Command and control and the market control as a way of ensuring universal Access?

There has been no clear cut consensus of what model of regulation or what combination of models of regulation should be adopted to either enhance or substitute the popular Command and control model. There have been suggestions on what form of innovative policy can be used in the light of the new challenge of new wireless systems that require spectrum. Matheson and Morris (20II) are encouraging the free market approach based on the inefficiencies of the command and control. The inefficiencies are borne out of the growing number of new technologies in the market competing for spectrum. They advise that regulators partition the spectrum across the dimension of space, time, frequency, and direction of propagation. The regulators will proceed to sell their rights to operators who will buy, sell or subdivide their partitions to enhance efficiency. The duty of the regulator will then be to maintain a database and a signal propagation model that facilitates transaction and enforcement. Satapathy and Peha (1996) noted that the unlicensed Commons and the Command and control are similar when it comes to spectrum sharing. They noted a lot of differences but one is important for this article. One is free spectrum and the other is paid 
for. In their submission, they threw the option of choice open while analysing the possible merits and demerits of unlicensed spectrum sharing. Licencing has been touted as a safe guard to ensuring quality. Svorny (1999) made an analysis of effect of licencing quality in different sectors of the economy. She queried the effect of licencing in on the quality of product delivered. In her analysis, high cost of entry was inimical to the entry of diverse players that would engender competition and innovation. Hence quality of service or product is affected as the existing service providers have no incentive to raise the bar especially if they are enjoying economics of scale. Although she had a broader outlook on policy and market entry, the same idea can be applied in the telecommunications industry. The unlicensed common's model has received great criticism from various sectors of the industry. The great question arises from the reliability aspect of an unlicensed spectrum. The issues of crowded interference, self-interference and costly network rips have been sighted as possible bottle necks to this fresh proposition on ground (Satapathy and Peha, 1996).

These misgivings have not stopped industry players from giving the idea a try. In the area of rural telephony, there have been the calls for the use of unlicensed spectrum. Recently there is a pilot test project by Townes telecommunications Inc. using a technology from $x G$ Technologies Incorporated called $x$ Max which will be initially deployed in Lewisville, Ark., as part of a test to gain Rural Utilities Service (RUS) certification, but Townes also plans to use the system in many of its other rural properties in Texas, Kansas, Pennsylvania, Colorado, Arkansas, Missouri and Florida (Wilson, 20II). The xMax uses cognitive radio that samples the airwaves to identify and use the best free channel and frequency band available at any given second. The pilot test of a new wireless system is designed to let rural carriers use unlicensed spectrum to offer mobile and fixed voice, text and, ultimately, broadband data service. Botswana is another country where Internet service providers use unlicensed spectrum band. In their own case they had a result, the number of broadband subscribers have increased due to cost reduction from using free spectrum (Openspectrum, 20II).

In this article, focus is not placed on the technical efficiency of the unlicensed spectrum or the removal of licence fees as an entry impediment. The focus is on how; the removal of licence and spectrum regulations for small business entrepreneurs can bring down the cost of deploying cheap network technologies like $\mathrm{Wi}-\mathrm{Fi}$ in rural areas. In
Ghana which is the test study here, Ghana does not need to lower the entry cost for bigger telecommunication networks because it will not be significant to their cost of operation. Hence the cost of going to the rural areas to deploy will still be high. But if the entry requirements for the small network operators who can start small Wi-Fi, $V$ sat companies in villages can be removed as an incentive, then investing in these villages will be a catchy idea.

\section{Method}

The case study investigation was on Ghana's telecommunications industry. Most of the results collated are results of earlier researches done by the author as well as the research done for this paper. The results for the earlier researches were not part of the research report. However they are used here because they are relevant to the discussion at hand.

An investigation was carried by reviewing literature and fieldwork using unofficial interviews with a few small network operators and ICT policy specialists. The aim of using these tools of investigation was to assess the entry trends of telecommunication providers in Ghana, their cost of acquiring spectrum and licenses. There was further investigation into the current trend in getting license for low cost technologies, spectrum fees, and regulatory fees to see how this affected market entry to the Ghanaian telecommunications market. Comparative analyses were made on the market entry requirements of both major and small network operators. The aim was to find out the effect of the respective market entry procedures in encouraging more service providers to invest telecommunications sector in Ghana. Further investigations were also made on the cost of deploying the major networks and the small networks in Ghana. The aim of this investigation was to find out if the proposed market incentive of Free spectrum alone would encourage local entrepreneurs to invest in rural areas. Information from that on the startup of major telecommunication networks in Ghana was a bit sketch, however information on the upgrade from $2 \mathrm{G}$ to $3 \mathrm{G}$ mobile technologies in Ghana gave an insight as to how much could have been spent in deploying the infrastructures.. These investigations allowed the researcher to identify the effect of market entry requirements in Ghana and how a further market incentive policy of free spectrum to small network operators can encourage small network provider to invest in rural Ghana. 


\section{Results}

\begin{tabular}{|l|l|l|}
\hline 2G & Operator & (Cost) US\$ Million \\
\hline \multirow{3}{*}{ License/ } & GLO & 50 \\
\cline { 2 - 3 } & & \\
\cline { 2 - 3 } & Scancom & 22.5 \\
\cline { 2 - 3 } & Millicom Gh Ltd & 22.5 \\
\cline { 2 - 3 } & & \\
\cline { 2 - 3 } & Kasapa (now Expresso) & 22.5 \\
\hline
\end{tabular}

Table I Cost of Spectrum/license for 2nd Generation mobile telephony license/ Data from Wikinvest (2009), Goschen (2007),

Tables I, and 2, are extrapolated from documentations from network operators, news dailies and NCA's annual reports. Table 3 is extrapolated from NCA's website. Before making a case for the removal of the cost of licenses for cheaper technologies, it was important to investigate the cost of licenses for the major network technologies in Ghana.

From table I, the least cost paid for 2 nd generation license/ spectrum in Ghana was US\$22.5 Million (Goschen, 2007). The amount of US $\$ 50$ million paid by GLO mobile is not for the 2 nd generation License/spectrum alone but for the 3 rd Generation license/spectrum as well (Yeboah, 2008). They are a new entrant so they bought both in a public tender. The amount was paid to the National Communications Authority (NCA), Ghana's telecommunications regulator. Each license was granted for 15 years.

\begin{tabular}{|c|c|c|}
\hline $3 G$ & Operator & (Cost) US\$ Million \\
\hline \multirow[t]{6}{*}{ License/Spectrum } & $\mathrm{GLO}$ & \multirow{6}{*}{$\begin{array}{l}\text { GLO paid } \$ 50 \text { Million } \\
\text { The rest paid NCA a combined } \\
\text { amount of GHC } 43.6 \text { Million }\end{array}$} \\
\hline & $\begin{array}{l}\text { ZAIN (now Bharti } \\
\text { Airtel), }\end{array}$ & \\
\hline & MTN (Scancom) & \\
\hline & Vodafone & \\
\hline & $\begin{array}{l}\text { Expresso (former } \\
\text { kasapa) }\end{array}$ & \\
\hline & Millicom & \\
\hline
\end{tabular}

Table 2 Cost of Spectrum/license for 3rd Generation mobile telephony license / Data from NCA Annual Report (2010), 
From table 2, It was difficult to get the actual amount paid by each operator for a third generation Mobile telephony license. However from the NCA report the combined amount was GH 43.6 (Ghana cedi) which is equivalent to US $\$ 28.8$ million for 15 years. The combined spectrum cost is cheap; however the cost of upgrade is high at
$\$ 120$ million. Huawei technologies got the contract for both MTN and Vodafone (Ghana News Agency, 2006. Field, 2009). MTN and ZAIN have deployed High Speed Download Packet Access (HSDPA). GLO is yet to commence operation, while Millicom (Tigo) has deployed 3G. There was no information on Expresso.

\begin{tabular}{|c|c|c|}
\hline VSAT/WiFi & Specification & Cost \\
\hline \multirow[t]{4}{*}{ Spectrum regulatory charges } & $\begin{array}{l}\text { Industrial Scientific and Medical radio band } \\
2 \mathrm{GHz} \text { band }(2.4000-2.4830) \text { and } 5.8 \mathrm{GHz} \\
\text { band }(5.77-5.850)\end{array}$ & $\$ 300$ per region \\
\hline & $\begin{array}{l}\text { Point-Point microwave link with bandwidth } \\
\leq 14 \mathrm{MHz}\end{array}$ & $\$ 1000$ \\
\hline & $\begin{array}{l}\text { Point-Point microwave link with bandwidth } \geq \\
14 \mathrm{MHz}\end{array}$ & $(\$ 1000)$ \\
\hline & Point Đmulti- Point microwave link 2x1Mhz & (\$3000 per region) \\
\hline \multicolumn{3}{|l|}{ Regulatory fee } \\
\hline \multirow[t]{3}{*}{ VSAT for public use (Urban) } & Application fee & $\$ 1000$ \\
\hline & Authorization charges & $\$ 2000$ \\
\hline & Annual regulatory fee & $\$ 2000$ per year per site \\
\hline \multirow{3}{*}{$\begin{array}{l}\text { VSAT terminal for public use } \\
\text { (Rural) }\end{array}$} & Application fee & $\$ 500$ \\
\hline & Authorization fee & $\$ 500$ \\
\hline & Annual regulatory fee & $\$ 250$ per site per year \\
\hline \multirow[t]{3}{*}{ VSAT network (DTH) } & Application fee & $\$ 1500$ \\
\hline & Authorization charges & $\$ 20000$ \\
\hline & Annual regulatory fee & $\$ 15000$ \\
\hline
\end{tabular}

Table 3 Spectrum and regulatory charges for VSAT/WiFi services and equipments/ Data from NCA (20II) 
The data from table 3 shows glaringly the wide disparity in the spectrum and regulatory charges for VSAT and WiFi operators in Ghana. It is also important to note that the regulatory charge for the Microwave link is also applicable to the fixed and mobile network operators who paid huge entry fee to join the Ghanaian telecommunications market. Hence since mobile networks use microwave links as one of their last mile infrastructure they have to pay US $\$ 3000$ for an area they want to penetrate. Please do note that these payments are one time payments unless otherwise stated as annual payments. However, the government of Ghana has reduced the annual regulatory charge for rural termination of VSAT services. Unfortunately as, it will be discussed later, it is still not enough incentive to encourage the entrepreneurs to go into the rural areas.

\begin{tabular}{|l|l|l|l|l|}
\hline ISPs & VSAT/Satellite Operators & $\begin{array}{l}\text { Mobile Telephone } \\
\text { Operators }\end{array}$ & $\begin{array}{l}\text { Cyber caf̌̌ } \\
\text { Operators }\end{array}$ & $\begin{array}{l}\text { Fixed Line Service } \\
\text { Operators }\end{array}$ \\
\hline 33 & $\begin{array}{l}\text { Some ISPs and companies } \\
\text { use VSAT }\end{array}$ & 6 & At least 82 & 2 \\
\hline
\end{tabular}

Table 4 Result of the a summary of ICT companies / Data from Business Ghana Directory (20II)

Table 4 shows a summary of an estimated number of ICT companies in Ghana. The market incentive seen in table I and 2 are less favorable to local entrepreneurs due to lack of capacity. The market incentive in table 3 enables local entrepreneurs to join the telecommunications market. Hence you have more Cyber Café operators and ISPs who are down the value chain than the foreign major network operators.

\begin{tabular}{|l|l|l|}
\hline Item & & Approximate cost \$ \\
\hline Renting an office premises & & $\$ 2000$. \\
\hline Bandwidth retransmission & $2 \mathrm{Mbps}$ & $\$ 7000$. \\
\hline Licensing fees & & \\
& $2.4 \mathrm{GHz}$ to & $\$ 300-\$ 500$ per region \\
& $5 \mathrm{Ghz}$ & \\
\hline
\end{tabular}

Table 5 Sample cost implications of establishing an Internet Service Providers in Ghana/ Data extrapolated from Dogbevi (2008) 
In Ghana the average start-up cost for a small internet Service Provider is between approximately US $\$ 10000$ and US\$ 15000 (Dogbevi, 2008).

\section{Discussion}

In Ghana, the cost of spectrum is embedded as part of the price for the licence. To buttress the argument for free spectrum for small network operators as an incentive to invest in rural areas, it was necessary to identify the spectrum requirements for the major and small network operators. Tables $\mathrm{I}$ and 2 represents data indicating how much each network operator paid for $2 \mathrm{G}$ and $3 \mathrm{G}$ licences. While table 3 represents data on how much it costs for smaller network operators to acquire licence in Ghana. Wi-Fi operators use in most cases frequencies at the $2 \mathrm{GHz}$ range of spectrum. It is important to note that operators in Ghana for both private and public networks use either $\mathrm{Wi}$-Fi with Powerline communications. There are different scenarios where these technologies are used either alone or in combination with other networks. In some other cases, Wi-Fi point to point links are used as the backhaul for the network. Another scenario abound where VSAT or Internet Protocol is used to link the existing Wi-Fi network with the outside world. The data from the (NCA) indicates that the amount of money operators pay for spectrum to transmit VSAT, Wi- $\mathrm{Fi}$ services in Ghana is far less than $1 \%$ of the total amount paid for $2 \mathrm{G}$ and $3 \mathrm{G}$ licences. A VSAT service in an urban area attracts a licencing fee of $\$ 5000$ when the licencing free, regulatory fee and the authorization fee are lumped up together. Similar service in the rural area attracts $\$ 1250$ annually. This is a far cry from the $\$ 22$ Million paid by GSM operators. The NCA allocated the $3 \mathrm{G}$ spectrum and licence at a reduced rate but it has still not made an impact on rural penetration of telecommunication services.

The difference in the impact in the market entry procedure between the 2G / $3 \mathrm{G}$ entry and that of the smaller network technologies can be seen in table 4. There are more ISPs than mobile and fixed network operators. Although an argument may be made that market entry requirements alone may not be the only reason for the small number of fixed and mobile operators. However, in Ghana as well as other countries in the world it is difficult to find many bidders bidding to roll out a GSM or UMTS network in a country. They are usually few and many at times it is the multinational telecommunication companies with significant financial might and technical expertise that bid for these licences. Many relatively small companies don't bid because of the huge financial commitment it requires. However, the positive externalities of these GSM and UMTS networks enable the downstream sector where we have ISPs, content providers, service aggregators etc. Hence market entry plays a role in having that small number.

However, the argument for a free spectrum wouldn't be valid if the cost of starting up a small network was not considered. In Ghana, the most ubiquitous small network provider is the ISP. In rural areas, setting up smaller telecentres as well as ISPs for on the spot as well as local area connectivity would be ideal. In South America, similar initiatives are dotted in rural and many at times remote areas. This enables these rural areas to be connected to the rest of the world. Table 5 is a rough estimate provided by ISP owners in Ghana. The estimate here is for a small ISP. When comparing the cost of setting up a small ISP which is between $\$ 10000$ and $\$ 15000$, to the cost of setting up a Radio Network Controller and upgrading software in order to upgrade a GSM network to a UMTS network. It is less than $1 \%$ of the cost. In Ghana MTN and Vodafone paid Huawei $\$ 120$ million to upgrade their networks.

Having read this analysis so far, one may be tempting to say the market incentives given to the small networks are alright as it is. The cost of entry is low; the cost of setting up a small network is low what else is needed? As stated earlier in this article, the rural areas aren't commercially viable. However in the cities, there are small challenges as well. At the moment lburst, An ISP sells the cheapest Modem at GHCI39 Ghana Cedi (US\$9I.7) and pre-paid vouchers for $220 M B$ with GHC 20 (US\$13.19) of free traffic. The antennas needed for wireless laptops sell between $\$ 15$ and $\$ 70$. Their cheapest reload voucher is GHC 50 Ghana Cedi (US\$32.9) and the highest is GHC 200 Ghana Cedi (US\$13I.9) (Iburst Africa, 20II). In the cities many can't afford these services, hence they visit internet cafes that retail an hour of access to the internet at an average cost of GHC I Ghana Cedi (US\$0.65). The inability for a lot of people to afford the service is because many Ghanaians in the cities survive on minimum wage and the cost of access to credit is high. The daily minimum wage in Ghana is GHC 3.73 Ghana Cedi (US\$ 2.46) (Ghana News Agency, 20II). In a month a minimum wage worker earns GHC III.9 Ghana Cedi (\$US 74). The average interest rate for credit from the bank is 25\% (Gtbank Ghana, 20II). Hence the small telecommunications provider grapples with paying the bank and seeking for a market share in a small market. 
However, if the licencing obligation is removed and free spectrum is granted to these small telecommunications providers, the annual recurring expenditure of paying for spectrum, regulatory fee and renewal of licencing can be used as an incentive to attract them into the rural areas. In the rural areas, real estate is far cheaper than those in the cities. This only applies to renting. Hence a small network provider will not be paying an equivalent of $\$ 2000$. With free spectrum granted, the amount of money saved from paying for spectrum and rent will enable the small operator build a small Wi-Fi network that will cater for a small village for a start. The network provider doesn't need fibre optic back-bone. A Wi-Fi back bone can be used instead. Small telecentres can be provided by the small network provider to grant access to villagers who can't afford customer premise equipment at a lower cost. This will not require a huge capital from the banks because the existing network provider is only expanding his reach with a small rural network. Some existing small operators with a good financial balance sheet can conveniently deploy the network without borrowing from the bank.

The free spectrum incentive will enable many small operators to deploy small networks in rural areas and even compete among themselves in the provision of the services. In other parts of the world there are similar cheap Wi-Fi initiatives that have succeeded even though free spectrum was not used as an incentive to lower the cost of diffusion and adoption of the service. In Bolivia, there are 3 overlapping $\mathrm{Wi}-\mathrm{Fi}$ hotspots at Sopachuy, a rural area of 1500 people (Townsend and Stern, 2006). The hotspots support data, computer based telephony and VOIP. Each Wi-Fi transceiver has an individual Internet Protocol Address which can be controlled and managed by any operator anywhere in the world. There is another similar network at an Amazonian region of Ecuador called Yachana. Here instead of using $\mathrm{Wi}-\mathrm{Fi}$ point to point network, VSAT is used to connect the Mesh to the outside world. At the Chancay - Huarai Valley, North of Peru, there is a similar network covering 22 hectares of land. The area is covered by $12 \mathrm{Wi}-\mathrm{Fi}$ backbone links and the cost of each tower, antenna and radio equipment at each site was between US\$ 1200 and US $\$ 1500$ (Townsend and Stern, 2006). Assuming an average of US $\$ 1500$ was spent per site, and then $\$ 18000$ was used to set up the network.

However, these possibilities can be fast tracked in rural Ghana and rural Africa at large if free spectrum will be granted as an incentive to entrepreneurs willing to invest in the rural areas. The possibilities facilitated by these technologies require a fundamental shift from governments. A lot of money is made by governments from taxes on both major and small network operators, spectrum licences, regulatory fees, interconnectivity, termination charges etc. Relinquishing free spectrum as an incentive for rural telecommunication development will go a long way in promoting the socio- economic wellbeing of the rural areas. E-commerce, E- governance, Ehealth and E-education are various possibilities by which rural dwellers can benefit from using ICTs. And most importantly, as the economy of the rural areas picks up, major networks will feel confident to come in and invest. With Free Spectrum for small network operators, the cost of deployment of the service will reduce even further to the level in which the rural dweller will be able to afford the telecommunication service.

This test carried on Ghana in this article is very possible to implement in rural areas of sub-Saharan Africa. Universal Access of telecommunication services is possible in Africa if the right market incentive is adopted to encourage the private sector to invest and make profit.

\section{References}

BANKOLE, A. (2009). Status of Services Sector Regulatory Reforms in Nigeria. http://www.ileap-jeicp. org/downloads/abuja_nov09/presentations /s5/bankole status of sectoral services regulatory_reforms in nigeria.pdf. [Assessed June 3, 20II]

BILESANMI, A. (20II). Nigerian Telecom Industry data 2010. http://www.cyberschuulnews.com/gallery.html. [Accessed June 20, 20II]

BUSINESS GHANA DIRECTORY (20II). Business Directory-IT.http://www.businessghana.com/portal/ directory/index.php?op=getSubDirectories\&category $=I T$

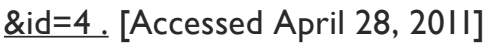

DOGBEVI, E (2008).Ghana's low internet penetration, high cost and national growth. http://www.ghanabusinessnews. com/2008/I2/06/ghanas-low-internet-penetration-highcost-and-national-growth . [Accessed April 28, 20II]

FALCH, M (2010). Telecom Infrastructure Regulation. Centre for Communications Media and Information technology Aalborg University Copenhagen. 
FDI (1999). Focus on the new Africa, Fact sheet on Foreign Direct investment. http://www.fdi.net/unctad/ fdiafrica_frame.htm. [Accessed June 2I, 20II]

FIELD, R (2009). MTN launches 3.5G services in Ghana. http://www.arabianbusiness.com/mtn-launches-3-5gservices-in-ghana-79996.html . [Accessed April 20, 20II]

FREMPONG, G. K., Atubra, W.H (200I). Liberalisation of Telecom: The Ghana's Experience. Telecommunication Policy, Vol 25 pp197-210

GHANA CONNECT (2010). Ghana Broadband Strategy 20I0.http://www.ghanaconnect.org.gh/wp-content/ uploads/2010/09/Ghana_Broadband_Strategy.pdf

[Accessed June 20, 20II]

GTBANK GHANA (20II). Base rate. http://www. gtbghana.com .[Accessed June 29, 20II]

GHANA NEWS AGENCY (2006). 300m Smart phones to be sold annually by 2013-Report. http://news.myjoyonline. com/business/200903/27408.asp. [Accessed April 20, 20II]

GHANA NEWS AGENCY (2010). New National Daily Minimum wage is 3.Il Cedis http://www.ghanaweb.com/ GhanaHomePage/NewsArchive/artikel.php?ID $=175749$. [Accessed June 18, 20II]

GHANA STATISTICAL SERVICE (2010). Preliminary result for Census 2010. http://www.statsghana.gov.gh/ index.html . [Accessed June 24, 20II]

GOSCHEN, B (2007). Overview on AreebaReport. http://docs.google.com/viewer?a=v\&q=cache :PI7ltghcFZQJ:www.mtn.com/mtn.group.web/ Uploads/35c4e404-b69e-4484a b5d2a d0813 5d77 4.pdf+scancom\%2Blicence $\% 2 B G h a n a \& h l=e n \& p i$ $\underline{d=b l \& s r c i d=}$ ADGEE Sj97D54 wYovkNt9 Ds27 XwSQ8GODCMXgC215I5MUPM-JSO16KJ4gc9adaohaUIN62p-gCeKVfpdt EPjtHV6 SMKv yHlf wN7qxYsHViZw eAC2jgbivnwqb470zDqKqG-fNHJ9Icjg\&sig=AHIEtbRV5s tN5qtNx7p-ilYUxVOIKA7BAg. [Accessed June 24, 20II]

IBURST AFRICA (20II). http://www.iburstafrica. $\mathrm{com} /$ ?c $=\mathrm{gh}$. [Accessed June 18, 20II]
MATHESON, R., Morris, A (200I) .The Technical Basis for Spectrum Rights: Policies to Enhance Market Efficiency. http://www.brookings.edu/ /media/Files/ rc/papers/2011/0303_spectrum_rights_matheson morris $/ 0303$ spectrum_rights matheson_morris.pdf [Assessed April 20, 201I]

MYITGHANA (2010).Internet bandwidth prices cut to half. http://www.myitghana.com/?p=164 . [Accessed May 3, 20II]

NCA (20II).Market Share Statistics 20I0. http://www.nca. org.gh/40/105/Market-Share- Statistics.html. [Accessed June 20, 20II]

NCA (201I). Regulatory Charges for Communication facilitiesandservicesin Ghana.http://nca.org.gh/downloads/ Regulatory Charges for Communication facilities and_services in_Ghana.pdf . [Accessed April 4, 20II]

NCA First Quarter Annual Report (2010). http://www. nca.org.gh/downloads/NCA $\% 20$ Ist $\% 20$ Quarter $\% 20$ Report\%202010-Final.pdf . [Accessed April 20, 20II]

NCC (20II). Annualized Telecoms Subscriber Data (200I - 2010). http://www.ncc.gov.ng/subscriberdata.htm. [Accessed June 20, 20II]

OPENSPECTRUM.INFO (20II). Botswana-Africa Regional Overview. http://www.volny.cz/horvitz/os-info/ botswana.html. [Accessed May 18, 20II]

PEHA,J.(20II).SpectrumSharingAmongWirelessSystems. http://www.ece.cmu.edu/ peha/spectrumsharing.html . [Accessed May 18, 20II]

SATAPATHY, Durga P. and Peha, J. M. (1996). Spectrum Sharing Without Licenses: Opportunities and Dangers. Department of Engineering and Public Policy. Paper 21. http://repository.cmu.edu/epp/2I. [AccessedApril20,20II]

SULLIVAN, Arthur; Sheffrin, Steven M. (2002). Economics: Principles in Action. New Jersey: Pearson Prentice Hall. ISBN 0-13-063085-3.

SVORNY, S (1999). Licensing, Market entry regulations. http://encyclo.findlaw.com/5/20book.pdf . [Accessed May $18,2011]$ 
THEFREEDICTIONARYBYFARLEX(20II).Public-Private Partnerships. http://encyclopedia.thefreedictionary.com/ Public+Private+Partnership . [Accessed April 30, 20II]

TOWNSEND, D. Stern, P. (2006). New Models for Universal Access in Latin America. http://www.regulatel. org/miembros/publicaciones/ESTU\%20DIOS/SERV\%20 UNIV/PPIAF/informe\%20final/draft\%20vf/Ab\%20\%20 Summary\%20v. [Accessed April 10, 20II]

WIKINVEST (2009). Millicom International Annual Report,2007. http://www.wikinvest.com/stock/Millicom International_Cellular_S.A._(MICC)/Ghana . [Accessed April 28, 20II]

WILSON, C (20II).Can Unlicensed Spectrum Solve Rural Broadband? http://www.lightreading.com/document. asp?doc_id=205774. [Accessed May 18, 20II]

YEBOAH, I (2008).NCA awards mobile licence to Nigeria's GLO Mobile http://news.myjoyonline.com/ business/200806/17307.asp . [Accessed April 20, 20II] 
J. Technol. Manag. Innov. 20II,Volume 6, Issue 3 